\section{Ebola, des premiers vaccins disponibles}

Baptiste Martin, Viktor Volchkov, Olivier Reynard

$>$ Ces dernières années, le virus Ebola a été responsable d'épidémies de grande ampleur. Les efforts de recherche ont permis la mise au point et l'évaluation sur le terrain de plusieurs candidats vaccins. À l'heure actuelle, deux sont déjà homologués et utilisés dans la lutte contre le virus en République démocratique du Congo. Cette revue se propose de faire le point sur les différents candidats vaccins, les essais cliniques qui ont été menés et les premiers résultats de terrain. <

\section{Ebola : épidémiologie et physiopathologie}

En février 2020, la République démocratique du Congo (RDC) voit s'achever dans la région du Kivu, la deuxième plus importante épidémie due au virus Ebola. Comme pour l'épidémie de 2013-2016 en Afrique de l'Ouest, c'est à nouveau le sous-type Zaïre du virus Ebola qui a refait surface [1]. Ce virus, d'ordinaire présent dans l'écosystème chez son réservoir potentiel, la chauve-souris, se transmet lors de rares concours de circonstance à I'homme. II a été identifié pour la première fois en 1976 après la survenue d'épidémies importantes à Yambuku, dans une région du nord du Zaïre (aujourd'hui République Démocratique du Congo) ainsi qu'à Nzara, dans la province ouest-équatoriale du Soudan. Les deux virus détectés en 1976 ont, par la suite, été identifiés comme étant les virus Ebola virus (EBOV) et Sudan virus (SUDV). À ces deux virus, sont venus s'ajouter, au fil des découvertes, quatre nouvelles espèces de virus Ebola : les virus Taï Forest (TAFV), Bundibugyio (BDBV), Reston (RESTV) et très récemment, le virus Bombali (BOMV) [2]. Alors qu'en 2013, les pays d'Afrique de l'Ouest (Guinée, Sierra Leone et Libéria) étaient pour la première fois confrontés à ce virus [3] $(\rightarrow)$ ), les régions d'Afrique centrale (Zaïre, RDC et République du (ongo ${ }^{1}$ ) ont fait face à maintes reprises à ce virus lors de 13 épidémies. Ainsi, l'année

$\rightarrow)$ Voir le Faits et chiffres de 0 . Reynard et al., $\mathrm{m} / \mathrm{s} \mathrm{n}^{\circ} 6-7$, juin-juillet 2014, page 671

Vignette (Photo @ Olivier Reynard)

1 Aussi appelé Congo, ou RDC, Congo-Kinshasa ou RD Congo, il se différencie de la République du Congo, également appelée Congo-Brazzaville.

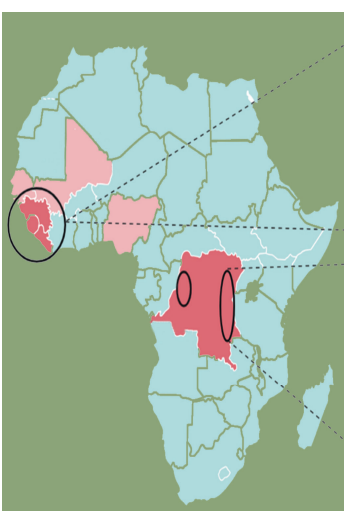

CIRI, Centre international de recherche en infectiologie, équipe Bases moléculaires de la pathogénicité virale, Univ Lyon, Inserm, U1111, Université Claude Bernard Lyon 1, CNRS, UMR5308, ENS de Lyon, F-69007, Lyon, France. olivier.reynard@inserm.fr

2018 a vu se succéder, à 6 jours d'intervalle, deux épidémies indépendantes l'une de l'autre en RDC. L'ampleur inattendue de l'épidémie d'Afrique de l'Ouest a permis une plus grande sensibilisation de la communauté internationale et la mise en place de stratégies thérapeutiques et préventives ambitieuses. Pour l'épidémie qui vient de se terminer en RDC (07/2018-02/2020), plus de 300000 personnes ont déjà été vaccinées contre ce virus grâce à l'utilisation de deux vaccins, le rVSVAGZEBOV-GP (ERVEBO ${ }^{\circledR}$ ) développé par Merck (301 785 vaccinés à ce jour) et le Ad26-EBO-Z/MVA-BN-Filo développé par Johnson \& Johnson (20339 vaccinés) [4]. Malgré cette vaccination d'une ampleur inégalée pour le virus Ebola, peu de résultats sur le suivi vaccinal des patients ont été obtenus, du fait du climat d'insécurité géopolitique régnant sur la région du Kivu au Nord-Ouest de la RDC, l'épicentre de l'épidémie [5]. Le vaccin $r V S V \triangle G-Z E B O V-G P$ avait déjà été utilisé auparavant dans différents essais cliniques à la fin de l'épidémie d'Afrique de l'ouest (programmes de vaccination « Ebola ça suffit », PREVAC, EBOVAC) et également lors de l'épidémie de la province d'Équateur en RDC en 2018 [6].

À l'exception des virus Reston et Bombali, dont la pathogénicité pour I'homme est absente ou inconnue, les quatre autres virus Ebola sont responsables d'une fièvre hémorragique aiguë et fatale dans 30 à $70 \%$ des cas, selon l'espèce mise en cause et la prise en charge des patients. Chez l'homme, cette infection apparaît après une phase d'incubation de 2 à 21 jours, les symptômes cliniques débutent par une série de signes non spécifiques comprenant une brusque poussée de fièvre et de forts maux de tête durant 5 à 7 jours. Les patients souffrent le plus souvent de cachexie, de vomissements, de diarrhée, de douleurs abdominales et d'une altération de leur état mental. Dans 10 à $50 \%$ des cas, des symptômes hémorragiques apparaissent avec notamment des hémorragies pétéchiales ${ }^{2}$, des saignements au

\footnotetext{
2 Lésion de la peau caractérisée par une issue de sang hors des vaisseaux. Elle détermine des taches rouges.
} 
niveau du tractus digestif, des conjonctives, et très souvent aux points d'injection des médicaments [7]. Selon les épidémies et le type de virus, la présence de symptômes hémorragiques est variable. Dans les infections fatales, les causes du décès sont liées à une réponse immunitaire non régulée, incapable de contrôler la réplication virale, ce qui induit une réponse cytokinique pro- et anti-inflammatoire, une défaillance multi-viscérale, une dérégulation du système cardio-vasculaire (diminution de la pression sanguine, déséquilibre de la biodistribution des fluides) et de l'hémostase [8]. En dépit de l'extrême pathogénicité du virus Ebola, des patients infectés survivent à la phase aiguë de la maladie et guérissent de l'infection en absence de tout traitement et ce, en contrôlant la réplication virale [8]. Une réponse inflammatoire précoce et mesurée semble avoir un rôle bénéfique dans le contrôle de l'infection par le virus Ebola ; cependant, les mécanismes moléculaires mis en jeu sont peu connus. De plus, lors des épidémies à virus $\varepsilon b o l a$, des cas d'infections humaines asymptomatiques ont été identifiés pour des individus directement exposés à des patients infectés par le virus Ebola [9].

Au cours de l'infection, des modifications immunitaires significatives et parfois précoces sont associées à différents pronostics. II semble qu'une faible réponse inflammatoire associée à une forte réponse polyclonale lymphocytaire $T$ spécifique du virus Ebola soit la clef du contrôle de la réplication virale. Inversement, la surexpression des marqueurs CTLA-4 (cytotoxic T-lymphocyte-associated protein 4) et PD-1 (programmed cell death-1) par les lymphocytes CD4 et CD8 est un facteur de pronostic défavorable [10]. Ces deux protéines sont des inhibiteurs de la réponse immunitaire T et notamment de la prolifération des lymphocytes T spécifiques. Chez les patients survivants, cette réponse cellulaire est principalement orientée contre la nucléoprotéine NP ainsi que la glycoprotéine GP et, dans une moindre mesure, la protéine de matrice VP40. Les différents vaccins et stratégies thérapeutiques testés par le passé ont montré que l'immunité cellulaire et humorale sont importantes pour le contrôle de la réplication virale, selon le type de vaccin envisagé. Les expériences de déplétion de populations lymphocytaires réalisées chez des singes vaccinés avec le rVSVAG-ZEBOV-GP, ont souligné l'importance critique de la réponse humorale et l'aspect facultatif de la réponse cellulaire [11]. À l'opposé, des tests sur les vaccins utilisant des adénovirus (voir plus loin) ont montré que ceux-ci avaient une protection fondée presque exclusivement sur la réponse cellulaire [12].

\section{Les stratégies vaccinales contre le virus Ebola}

Étant donné l'état d'urgence face à l'ampleur des dernières épidémies dues au virus Ebola, de nombreux efforts en recherche et développement ont été investis pour coordonner le financement, le développement, les tests et l'utilisation de nouveaux vaccins antiEbola. Actuellement, seul deux vaccins ont été validés par les hautes autorités de santé, huit candidats vaccins sont en cours d'évaluation à différents stades de qualification dans le cycle clinique et de nombreuses preuves de concept sont documentées au stade préclinique $[13,14]$. Ces vaccins sont classés par l'Organisation mondiale de la santé (OMS) en trois catégories (Tableau l) : la catégorie 1 pour les vaccins à vecteur non réplicatif, la catégorie 2 pour les vaccins à vecteur réplicatif et la catégorie 3 pour les autres types de vaccins. Les vaccins de catégories 1 et 2 utilisent des vecteurs viraux non-Ebola modifiés (réplicatifs ou non) dits « recombinants » qui ont la double tâche de présenter des antigènes du virus Ebola (principalement la glycoprotéine de surface GP) et de stimuler la réponse immunitaire. Chaque catégorie est illustrée ci-dessous par un exemple de stratégie vaccinale.

Les vaccins de catégorie 1 , adaptés d'un virus vecteur non réplicatif, ont l'avantage de présenter une plus grande innocuité, notamment envers des personnes immunodéprimées, mais ils peuvent nécessiter l'injection de plusieurs doses et notamment de stratégie dite «primeboost » (amorce-rappel) pour assurer une bonne immunisation. Différents candidats vaccins ont été décrits dans cette catégorie, plusieurs reposant sur un type de vecteur viral classiquement utilisé en vaccinologie, les adénovirus. L'adénovirus humain de sérotype 26 (Ad26) et l'adénovirus du chimpanzé de sérotype 3 (ChAd3) recombinants codant tous deux la glycoprotéine de surface GP d'EBOV (souche Mayinga) ont été respectivement développé par Janssen Vaccines, Johnson\&Johnson (Ad26-ZEBOV) (Figure 2A, Tableau I) et Glaxo-SmithKline (ChAd3-EBO-Z) (Tableau I). Ces vecteurs ont été choisis en primo vaccination car ils ont l'avantage de présenter contre eux une faible immunité préexistante chez l'homme et donc une potentielle meilleure efficacité immunologique, comparativement à d'autres sérotypes d'adénovirus, comme l'Ad5 classiquement utilisé en stratégie vaccinale [15]. L'utilisation d'une injection de rappel (stratégie «prime-boost ») fondée sur le virus de la vaccine modifiée (souche Ankara, MVA) recombinant codant les GP d'EBOV (souche Mayinga), de SUDV (souche Gulu) et de MARV (souche Musoke), ainsi que la nucléoprotéine de TAFV (MVA-BN-Filo), 56 jours après injection de l'Ad26-ZEBOV, permet d'améliorer très nettement la durabilité de la protection immunitaire [16-18] (Figure 2A). En phase I d'évaluation clinique, ce candidat vaccin a montré une bonne tolérance chez l'homme associée à une réponse immunitaire notable [16-18]. Les essais de phases II/III en cours confirment les résultats de phase I dans les différentes populations testées (plus de 6500 personnes au total). Ce vaccin est en cours de demande d'autorisation de mise sur le marché (AMM) auprès de la Food and Drug Administration (FDA) et de l'European Medicines Agency (EMA). Comme pour l'Ad26ZEBOV, d'autres stratégies utilisant différents sérotypes d'adénovirus (Ad5) (Tableau I) sont actuellement à l'étude à différents stades cliniques. 


\begin{tabular}{|c|c|c|c|c|c|}
\hline $\begin{array}{l}\text { Candidats } \\
\text { vaccins }\end{array}$ & Exploitants, pays & Souches virales & $\begin{array}{l}\text { Phase } \\
\text { clinique }\end{array}$ & $\begin{array}{l}\text { Nb total } \\
\text { de sujets }\end{array}$ & Références \\
\hline \multicolumn{6}{|c|}{ Catégorie 1 - Vaccins à vecteur non réplicatif } \\
\hline $\begin{array}{l}\text { Ad26-ZEBOV/MVA- } \\
\text { BN-Filo }\end{array}$ & $\begin{array}{l}\text { Janssen Vaccines (Johnson \& Johnson), } \\
\text { États-Unis }\end{array}$ & EBOV Mayinga & III & $>6500$ & {$[13,14]$} \\
\hline ChAd3-EBOV-Z & $\begin{array}{l}\text { Sabin Vaccines Institute \& GSK, } \\
\text { États-Unis/Russie }\end{array}$ & EBOV Mayinga & II & $>5600$ & {$[15]$} \\
\hline Ad5-عBOV & $\begin{array}{l}\text { CanSino Biologics Inc. \& Beijing } \\
\text { Institute of Biotechnology, Chine (RPC) }\end{array}$ & EBOV Makona & II & $>681$ & {$[16,17]$} \\
\hline \multicolumn{6}{|c|}{ Catégorie 2 - Vaccins à vecteur réplicatif } \\
\hline rVSVAG-ZEBOV-GP & Merck, Allemagne & EBOV Kikwit & III & $>200000$ & {$[18-21]$} \\
\hline Gamevac-Combi & $\begin{array}{l}\text { Gamaleya Research Institute of } \\
\text { Epidemiology and Microbiology, Russie }\end{array}$ & EBOV Makona & III & $>2000$ & [22] \\
\hline \multicolumn{6}{|c|}{ Catégorie 3 - Autres stratégies vaccinales } \\
\hline Delta VP30 & $\begin{array}{l}\text { University of Tokyo \& Waisman } \\
\text { Biomanufacturing, Japon et États-Unis }\end{array}$ & EBOV & 1 & nd & {$[23-25]$} \\
\hline INO-4201 & Inovio Pharmaceuticals, États-Unis & $\begin{array}{l}\text { Souches EBOV (épidémies } \\
\text { de } 1978 \text { à 2008) }\end{array}$ & 1 & $>230$ & [26] \\
\hline EpivacEbola & Rospotrebnadzor, Russie & EBOV Makona & 1 & $>300$ & N.D. \\
\hline $\begin{array}{l}\text { Nanoparticle } \\
\text { recombinant } \\
\text { Ebola GP vaccine }\end{array}$ & Novavax, États-Unis & EBOV Makona & 1 & $>182$ & [27-29] \\
\hline
\end{tabular}

Tableau I. Point sur l'avancement du développement clinique des différents candidats vaccins contre le virus $\varepsilon$ bola. Ce tableau présente les différents candidats vaccins par catégorie et leur avancement dans leur développement clinique ainsi que leur déploiement dans le cadre d'un usage compassionnel suite aux récentes épidémies. Les stratégies vaccinales en vert ont récemment reçu une autorisation de mise sur le marché par les autorités de santé et une qualification par l'OMS. RPC : République Populaire de Chine ; N.D. : non disponible (voir également https://medecine sciences.org/10.1051/medsci/2020174/olm).

À l'inverse des vaccins de catégorie 1 , les vaccins de catégorie 2, utilisant des virus vecteurs atténués mais toujours capables de se répliquer, permettent une réponse immunitaire plus forte et plus durable mais ils sont moins adaptés pour les populations au statut immunitaire affaibli (jeunes enfants, personnes âgées, etc.). Plusieurs vecteurs viraux ont été utilisés, en particulier des virus appartenant au même ordre phylogénétique qu'Ebola, les Mononegavirales ${ }^{3}$ (des virus à ARN simple brin monocaténaire), comme le virus de la stomatite vésiculaire (VSV). L'utilisation de ce rhabdovirus comme outil vaccinal est intéressante car il n'existe pas d'immunité contre ce virus chez l'homme [19]. Préalablement atténué, il a en effet servi de plateforme pour développer le candidat vaccin rVSVAG-ZEBOV-GP (V920) (Figure 2B, Tableau I) mis au point par l'agence de santé publique canadienne puis exploité par Merck.

\footnotetext{
3 Les Mononegavirales sont un ordre de virus à ARN monocaténaire de polarité négative et à génome non segmenté. On y trouve notamment les familles: Bornaviridae (le virus de la maladie de Borna); Rhabdoviridae (virus de la rage); Filoviridae (virus Marburg); et Paramyxoviridae (virus de la maladie de
} Newcastle, virus de la rougeole, virus Nipah).
Le virus de la stomatite vésiculaire a été modifié par génétique inverse pour perdre l'expression de sa glycoprotéine de surface et exprimer à sa place celle du virus Ebola (souche Kikwit) $[20,21]$. Dans le cadre de plusieurs consortiums internationaux, huit essais de phases I réalisés dans différents pays en Amérique du Nord et en Afrique [22, 23], puis grâce à une étude de phase II, à un essai de phase II/III, et à deux programmes de phase III $[24,25]$, ce vaccin, renommé par l'industriel $\varepsilon R V \varepsilon B 0^{\oplus}$, a semblé montrer une efficacité de $100 \%$ contre le virus dans un contexte épidémique [24]. En effet, l'étude «Ebola ça suffit », coordonnée par l'OMS [24], a, d'une part, confirmé l'efficacité du vaccin sur le terrain, mais a, d'autre part, permis de démontrer l'intérêt d'une stratégie de vaccination en anneau ${ }^{4}$ pour juguler une épidémie

\footnotetext{
${ }^{4}$ De proche en proche à partir des personnes contacts qui sont recherchées.
} 


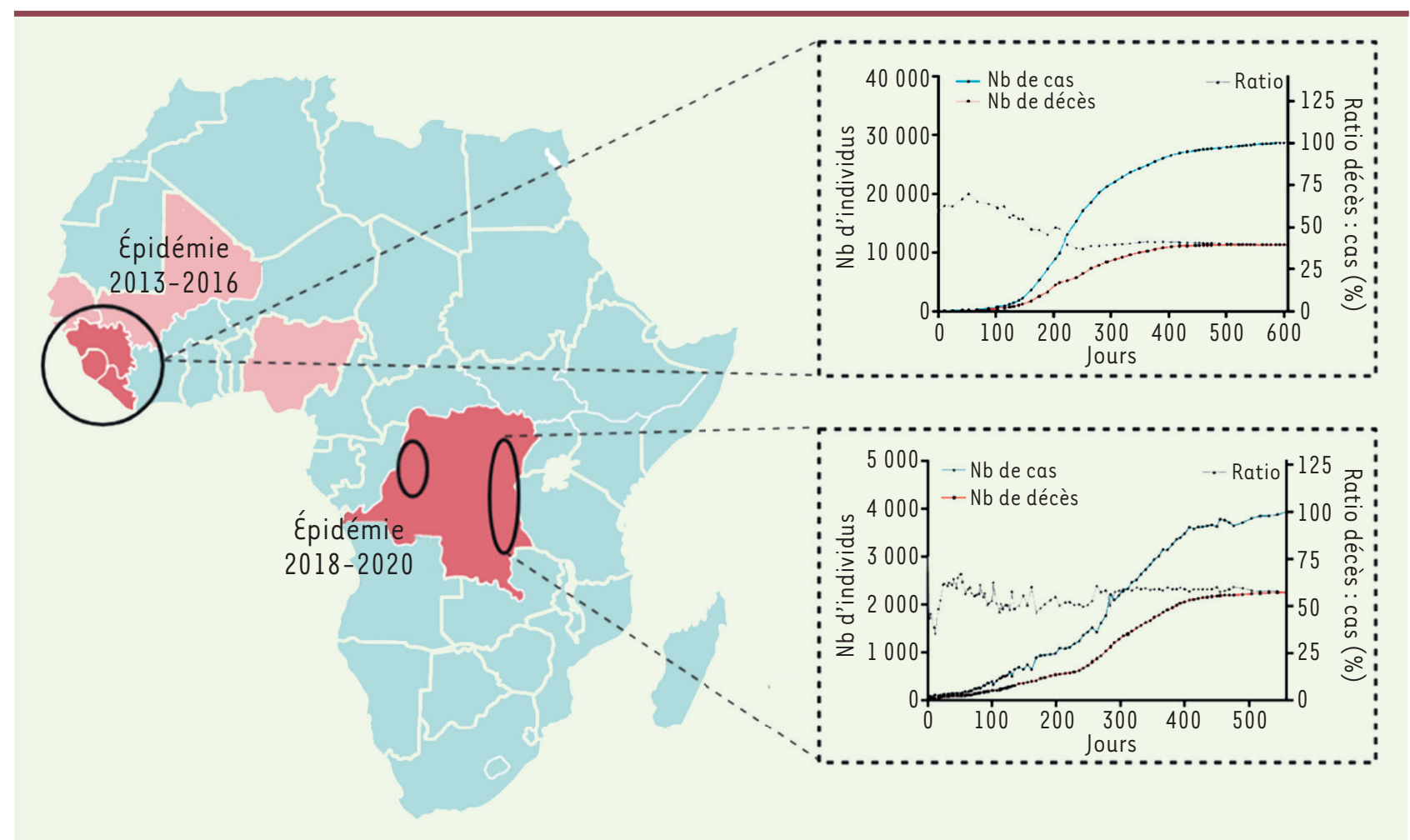

Figure 1. Suivi des récentes épidémies à virus Ebola. L'épidémie due au virus Ebola de 2013-2016 a sévèrement touché l'Afrique de l'Ouest, en particulier la Sierra Léone, le Libéria et la Guinée (en rouge foncé dans le cercle à gauche), avec des cas confirmés dans les pays alentours (Nigeria, Mali, Sénégal, en rouge pâle). Plus récemment (2018-2020), la République démocratique du Congo (RDC, en rouge foncé au centre) a connu deux épidémies distinctes sur son territoire (région du Kivu, cercle à gauche, et province d’équateur, cercle à droite). Pour ces épidémies, un grand nombre de cas ont été recensés : plus de 28600 en Afrique de l'ouest et plus de 3400 en RDC, soit bien plus que l'ensemble des cas recensés durant l'ensemble des épidémies précédentes. Ces épidémies ont également fait un grand nombre de victimes, plus de 11300 entre 2013 et 2016 (40\% de mortalité) et plus de 2200 entre 2018 et 2020 (57\% de mortalité).

à virus Ebola. Conjointement, l'initiative PREVAC, lancé en 2017, est un essai clinique académique majeur en cours qui permettra de comparer l'efficacité du vaccin rVSVAG-ZEBOV-GP à celle de l'Ad26-ZEBOV et dont les résultats sont attendus prochainement. Le vaccin rVSVAG-ZEBOV-GP est le premier des deux vaccins à avoir reçu une autorisation de mise sur le marché de la part de la FDA et de l'EMA fin 2019.

Le virus $r V S V \triangle G-Z E B O V-G P$ étant un virus réplicatif, il induit néanmoins une virémie transitoire que l'on retrouve chez une grande majorité des personnes vaccinées, avec une amplitude et une durée notamment plus importante chez les enfants. Dans quelques cas, cette virémie a été associée à une libération de virus vaccinaux dans la salive ou l'urine [26]. Plusieurs effets secondaires significatifs mais transitoires ont également été rapportés, en particulier de la fièvre, des myalgies, maux de tête et arthralgies, qui ont été associés à l'amplitude de la réponse lymphocytaire T avec une réaction proinflammatoire (avec production d'interleukine 2 [IL-2] et d'interféron gamma [INF $\gamma]$ ) [22, 23, 27-29]. Une étude porte actuellement sur l'évaluation d'une version modifiée du rVSVAG-ZEBOV-GP afin, notamment, de réduire ses effets secondaires (particulièrement au niveau articulaire). Cette version encore plus atténuée du rVSV, le
rVSVN4CTI-EBOVGPI, a été testé en phase I aux ÉtatsUnis et a montré une réponse humorale chez $100 \%$ des personnes vaccinées et l'absence de manifestation articulaire secondaire [30]; il reste à connaître son efficacité et la durabilité de sa protection.

D'autres stratégies vaccinales fondées sur l'utilisation d'autres Mononegavirales vecteurs [31,32] (Tableau 1), comme le virus parainfluenza humain sérotype 3 (hPIV3), sont en cours de développement clinique [33]. Bien qu'à un stade encore précoce, I'utilisation de ce vecteur hPIV3 pourrait se révéler particulièrement intéressante car ce virus est délivrable par aérosol, évitant ainsi l'usage de seringues [34].

Dans la catégorie 3, sont regroupées les différentes stratégies vaccinales ne faisant pas appels à des vecteurs viraux. Celles-ci sont très diverses, allant du virus inactivé à des cocktails de peptides et à I'insertion/délétion de gènes viraux (Tableau I). Une stratégie vaccinale prometteuse, nommée Delta VP30, 
A Vaccin non réplicatif (catégorie 1) : Ad26-ZEBOV + MVA-BN-Filo

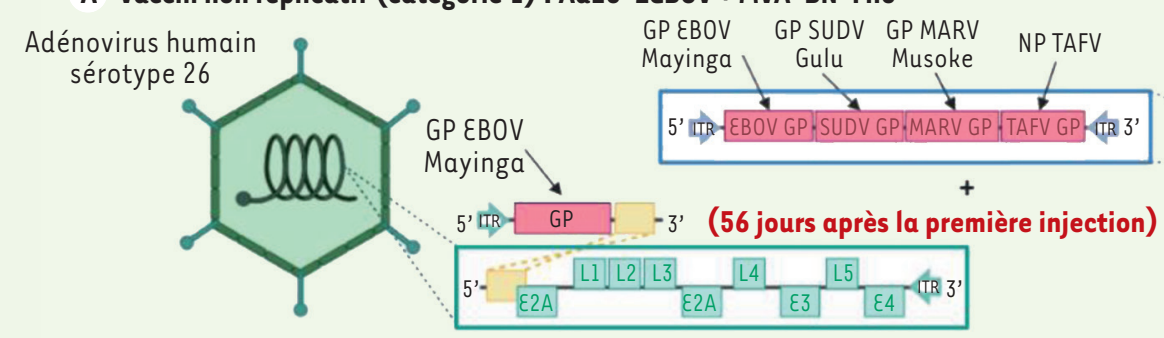

Virus de la vaccine

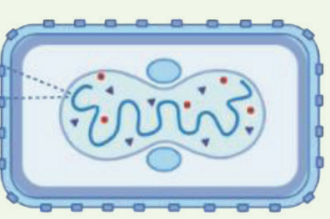

B Vaccin réplicatif (catégorie 2) : rVSV $\Delta G-Z E B O V-G P$

GP EBOV Virus de la stomatite vésiculaire

Kikwit

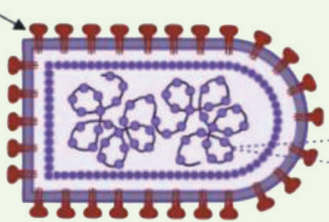

VSV

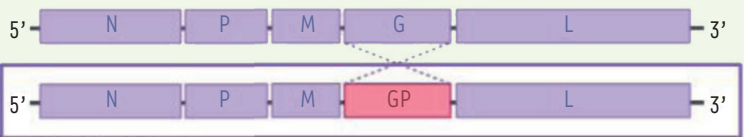

rVSVAG-ZEBOV-GP

C Autres Vaccins (catégorie 3) : عBOVAVP30

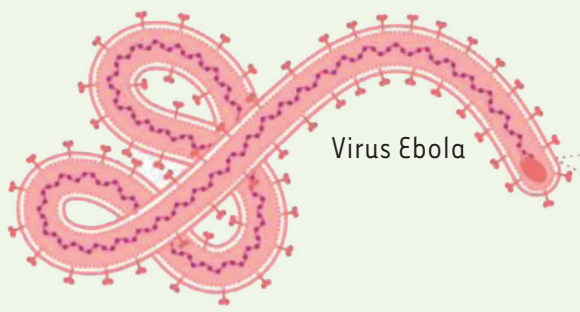

EBOV

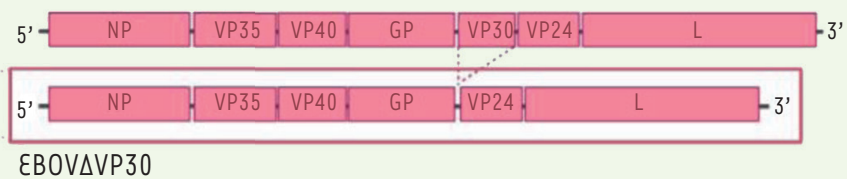

Figure 2. Exemples de constructions vaccinales contre le virus Ebola. Les différentes stratégies vaccinales sont réparties en trois catégories. A. La catégorie 1 est composée de vaccins à vecteur non réplicatif comme l’Ad26-ZEBOV pour lequel un adénovirus humain de sérotype 26 (Ad26) a été modifié de manière à coder dans son génome la GP du virus Ebola Zaïre (EBOV) souche Mayinga. Pour une meilleure immunisation, ce vaccin est associé à un « booster » composé d'un vecteur dérivé du virus de la vaccine codant les GP de différents filovirus (EBOV souche Mayinga, દbola Sudan (SUDV) souche Kulu, virus Marburg (MARV) souche Musoke) et la nucléoprotéine NP du virus Ebola Taï Forest (TAFV). B. La catégorie 2 regroupe des vaccins à vecteur réplicatif comme le rVSVAG-ZEBOV-GP dérivé du virus de la stomatite vésiculaire (VSV) où le gène de la glycoprotéine de surface G (violet) du VSV a été remplacé par celui de la glycoprotéine GP d'EBOV souche Kikwit (en rouge). C. La troisième et dernière catégorie contient les autres stratégies vaccinales telle que le virus Ebola dont la protéine VP30, un cofacteur de transcription du virus, a été retirée du génome viral, limitant ainsi sa réplication.

repose sur la substitution de la séquence codante de la protéine VP30 dans le génome du virus Ebola [35] (Figure 2C, Tableau I). Cette protéine est un co-facteur de la polymérase virale. Sa suppression préserve l'intégrité structurale et l'infectiosité du virus mais le rend non réplicatif. Cette stratégie a été proposée par le Yoshihiro Kawaoka, au Japon en 2008, et a montré une très bonne efficacité chez le primate [36]. Après une phase d'optimisation préclinique pour inactiver le virus et ainsi prévenir le risque de réintégration de VP30, le candidat vaccin ferait aujourd'hui l'objet d'une étude de phase I au Japon, bien qu'aucune déclaration de protocole clinique n'ai pu être identifiée [37]. D’autres stratégies sont également en cours d'évaluation clinique (Tableau I), comme le candidat INO4201, développé par Inovio Pharmaceuticals, qui repose sur des plasmides permettant l'expression de la GP de différentes souches de virus Ebola [38], ou encore le candidat vaccin développé par Nova- vax qui est constitué de GP recombinante greffée à des nanoparticules injectables $[39,40]$.

Bien que $\varepsilon B O V$ ait été responsable des dernières épidémies, l'histoire a montré que d'autres virus du genre Ebolavirus pouvaient entraîner des épidémies en Afrique. Ces virus sont ré-émergents, ce qui sousentend qu'à chaque épidémie, la souche infectieuse provient à nouveau du réservoir, soit directement soit indirectement, mais pas d'une chaîne de transmission inter-humaine continue. Se pose donc ainsi le problème de la variabilité des souches et donc de leurs potentielles différences dans la réponse à la vaccination. Dans le cas d'EBOV, plusieurs études ont montré l'existence d'une protection croisée vis-à-vis de différentes souches du virus [41]. La faible varia- 
bilité intra-espèce de la séquence protéique de la glycoprotéine GP explique cette observation (avec un minimum de similarité de $97 \%$ ). Cependant, la protection croisée entre les différents virus Ebola (TAFV, SUDV, BDBV, etc.) est moins connue. Ainsi, des animaux vaccinés avec le rVSV $\triangle G-Z E B O V-G P$ ont montré une protection croisée contre TAFV ou BDBV. Mais des animaux vaccinés avec un rVSVAGTAFV-GP n'ont pas survécu à une infection par EBOV ou BDBV [42]. De façon plus générale, il est connu que, parmi tous les antigènes principaux des filovirus, la glycoprotéine induit l'immunité d'espèce la plus spécifique [43]. Ainsi, soit les vaccins multivalents démontreront leur potentiel, soit, plus probablement, il faudra constituer des stocks de vaccins contre les principales souches pathogènes ( $\varepsilon B O V$, SUDV, BDBV) afin de se tenir prêts à endiguer la survenue d'une nouvelle épidémie.

\section{Problématiques socio-démographiques}

Les enfants en bas âge, les femmes enceintes, les personnes âgées, les personnes séropositives pour le virus de l'immunodéficience humaine (VIH) représentent les populations les plus à risque dans les épidémies dues au virus Ebola. Jusqu'à très récemment, l'absence de données sur leur sensibilité aux différents vaccins les écartait des protocoles de vaccination.

Des études récentes ont montré l'innocuité du vaccin rVSVDGZEBOV-GP pour les enfants [24]. Pour les femmes enceintes, le résultat est encore incertain car l'échantillonnage étant limité, le risque d'augmentation de fausse couche (multiplié par 1,35) observé lors de I'étude de phase II/III STRIVE (Sierra Leone trial to introduce a vaccine against Ebola) reste encore aujourd'hui à être confirmé par une étude de plus grande ampleur [44]. Malgré ces incertitudes, depuis juin 2019, les femmes enceintes peuvent recevoir en RDC le rVSVAG-ZEBOV-GP et, depuis novembre 2019, les enfants de plus de 1 an et les femmes enceintes reçoivent le Ad26-ZEBOV/MVA-BN-Filo.

Concernant les personnes séropositives pour le VIH, la seule étude relatant leur vaccination indique l'innocuité des vaccins rVSVAGZEBOV-GP et ChAd3-EBO-Z mais, là encore, l'échantillonnage restreint (78 volontaires) ne permet pas de conclusion définitive. II est néanmoins intéressant de noter qu'une réponse immunitaire a pu être mesurée chez ces patients, bien que d'ampleur plus limitée que chez les personnes séronégatives [45].

\section{Conclusion}

À l'heure actuelle, deux vaccins contre le virus Ebola sont disponibles pour endiguer les épidémies. L'occurrence inattendue des épidémies, tant sur les plans chronologique que géographique, rend la vaccination préventive des populations difficile. Les vaccins contre le virus Ebola resteront, nous semble-t-il, des vaccins qui permettent de bloquer l'expansion des épidémies, plus que de prévenir leur apparition. Les études de phase I/II ont montré pour tous les candidats vaccins un bénéfice-risque très en faveur de la vaccination, avec un nombre limité d'effets secondaires et une efficacité qui semble très intéressante, bien que, pour le moment, difficilement appréciable par manque de publication relatant un effet direct sur l'expansion des épidémies. Toutefois, alors que certains rapports indiquent une protection quasi totale par la vaccination, d'autres études soulignent la présence dans les centres de traitement, de quelques personnes vaccinées et pourtant malade du virus $[46,47]$. II sera nécessaire d'étudier à l'avenir s'il s'agit d'absence de réponse au vaccin ou d'un problème de délai entre la vaccination et la contraction de l'infection. Une analyse de plus grande ampleur permettra de mieux évaluer la proportion réelle de ces cas et de comprendre les raisons de ces quelques échecs vaccinaux. Dans le futur, le retour d'expérience de l'épidémie survenue dans la province du Kivu en République démocratique du Congo permettra de mieux approfondir les modalités de fonctionnement de ces vaccins actuellement disponibles. Des études sont encore en cours afin de mieux définir les doses nécessaires, la durée de l'immunité et la nécessité ou non d'avoir recours à un rappel vaccinal. Cette question du rappel vaccinal (actuellement posée pour l'Ad26/ChAd3 - MVA-BN-Filo) est d'importance car la mise en place de ce type de vaccination présente des inconvénients logistiques et financiers [48].

$\varepsilon n$ conclusion, la disponibilité de vaccins contre le virus Ebola est à présent un atout majeur pour lutter contre les futures ré-émergences de ce virus, les stratégies vaccinales restent à affiner et la compétition actuelle entre les différentes stratégies de vaccination (et compagnies pharmaceutiques) devrait permettre rapidement l'essor de vaccins à l'efficacité robuste et durable $\diamond$

\section{SUMMARY}

Ebola, the first vaccines available

In the recent years, Ebola virus has been responsible for several major epidemics. Research efforts have allowed the development and evaluation in the field of several vaccine candidates. At present, two of them are already approved and used in the fight against the virus in the Democratic Republic of Congo. This review aims to describe the different candidates, the clinical trials that have been conducted as well as the first results in the field. $\diamond$

Voir Matériel supplémentaire sur le site de médecine/sciences https:// medecinesciences.org/10.1051/medsci/2020174/olm

\section{REMERCIEMENTS}

Ce travail a été supporté par le financement EBODYSREG.

\section{LIENS D'INTÉRÊT}

Les auteurs déclarent n'avoir aucun lien d'intérêt concernant les données publiées dans cet article. 


\section{RÉFÉRENCES}

1. Ilunga Kalenga 0, Moeti M, Sparrow A, et al. The ongoing Ebola epidemic in the Democratic Republic of Congo, 2018-2019. N Engl J Med 2019 ; $381: 373-83$.

2. Goldstein T, Anthony SJ, Gbakima A, et al. The discovery of Bombali virus adds further support for bats as hosts of ebolaviruses. Nat Microbiol $2018 ; 3: 1084-9$

3. Reynard 0 , Volchkov $V$, Peyrefitte $C$. Une première épidémie de fièvre à virus Ebola en Afrique de l'Ouest. Med Sci (Paris) $2014 ; 30: 671-3$.

4. https://www.who.int/publications/i/item/ebola-virus-disease-democratic-republic-of-congoexternal-situation-report-85-2019

5. Editorial. DR Congo: managing Ebola virus in war. Lancet $2018 ; 392: 1280$.

6. Wells CR, Pandey A, Parpia AS, et al. Ebola vaccination in the Democratic Republic of the Congo. Proc Natl Acad Sci USA 2019; 116 : 10178-83.

7. Geisbert TW, Hensley LE. Ebola virus: new insights into disease aetiopathology and possible therapeutic interventions. Expert Rev Mol Med 2004 ; 6 : 1-24.

8. Reynard $S$, Journeaux $A$, Gloaguen $\varepsilon$, et al. Immune parameters and outcomes during $\varepsilon$ bola virus disease. JCl Insight 2019 ; 4.

9. Diallo MSK, Rabilloud M, Ayouba A, et al. Prevalence of infection among asymptomatic and paucisymptomatic contact persons exposed to Ebola virus in Guinea: a retrospective, crosssectional observational study. Lancet Infect Dis 2019 ; 19 : 308-16.

10. Ruibal $P$, Oestereich L, Lüdtke $A$, et al. Unique human immune signature of Ebola virus disease in Guinea. Nature $2016 ; 533: 100-4$.

11. Marzi A, Engelmann F, Feldmann F, et al. Antibodies are necessary for rVSV/ZEBOV-GP-mediated protection against lethal Ebola virus challenge in nonhuman primates. Proc Natl Acad Sci USA $2013 ; 110: 1893-8$.

12. Sullivan NJ, Hensley L, Asiedu C, et al. CD $8{ }^{+}$cellular immunity mediates $r A d 5$ vaccine protection against Ebola virus infection of nonhuman primates. Nat Med $2011 ; 17$ : 1128-31.

13. Matz KM, Marzi A, Feldmann H. Ebola vaccine trials: progress in vaccine safety and immunogenicity. Expert Rev Vaccines 2019 ; 18 : 1229-42.

14. Lévy $Y$, Lane $C$, Piot $P$, et al. Prevention of Ebola virus disease through vaccination: where we are in 2018. Lancet $2018 ; 392: 787-90$.

15. Geisbert TW, Bailey M, Hensley L, et al. Recombinant adenovirus serotype 26 (Ad26) and Ad35 vaccine vectors bypass immunity to $\mathrm{Ad} 5$ and protect nonhuman primates against ebolavirus challenge. J Virol $2011 ; 85: 4222-33$.

16. Milligan ID, Gibani MM, Sewell R, et al. Safety and immunogenicity of novel adenovirus type 26 and modified vaccinia Ankara-vectored Ebola vaccines: a randomized clinical trial. JAMA 2016; $315: 1610-23$.

17. Mutua G, Anzala 0 , Luhn K, et al. Safety and immunogenicity of a 2-dose heterologous vaccine regimen with Ad26.ZEBOV and MVA-BN-Filo Ebola vaccines: 12 -month data from a phase 1 randomized clinical trial in Nairobi, Kenya. J Infect Dis 2019; $220: 57-67$.

18. Anywaine Z, Whitworth $\mathrm{H}$, Kaleebu P, et al. Safety and immunogenicity of a 2-dose heterologous vaccination regimen with Ad26.ZEBOV and MVA-BN-Filo Ebola vaccines: 12-month data from a phase 1 randomized clinical trial in Uganda and Tanzania. J Infect Dis $2019 ; 220: 46-56$.

19. Geisbert TW, Feldmann H. Recombinant vesicular stomatitis virus-based vaccines against Ebola and Marburg virus infections. J Infect Dis 2011 ; 204 (suppl 3) : S1075-81.

20. Geisbert TW, Daddario-Dicaprio KM, Lewis MG, et al. Vesicular stomatitis virus-based ebola vaccine is well-tolerated and protects immunocompromised nonhuman primates. PLoS Pathog $2008 ; 4$ : el000225.

21. Geisbert TW, Geisbert JB, Leung A, et al. Single-injection vaccine protects nonhuman primates against infection with Marburg virus and three species of Ebola virus. J Virol 2009 ; $83: 7296-304$.

22. Huttner A, Dayer J-A, Yerly S, et al. The effect of dose on the safety and immunogenicity of the VSV Ebola candidate vaccine: a randomised double-blind, placebo-controlled phase $1 / 2$ trial. Lancet Infect Dis 2015 ; 15 : 1156-66.

23. Agnandji ST, Huttner A, Zinser ME, et al. Phase 1 trials of rVSV Ebola vaccine in Africa and Europe. $N$ Engl J Med 2016 ; 374 : 1647-60.

24. Henao-Restrepo AM, Camacho A, Longini IM, et al. Efficacy and effectiveness of an rVSV-vectored vaccine in preventing Ebola virus disease: final results from the Guinea ring vaccination, openlabel, cluster-randomised trial (Ebola ça suffit !). Lancet 2017 ; 389 : 505-18.

25. Halperin SA, Arribas JR, Rupp R, et al. Six-month safety data of recombinant vesicular stomatitis virus-Zaire Ebola virus envelope glycoprotein vaccine in a phase 3 double-blind, placebocontrolled randomized study in healthy adults. J Infect Dis $2017 ; 215: 1789-98$.

26. Bache $B E$, Grobusch MP, Agnandji ST. Safety, immunogenicity and risk-benefit analysis of rVSV- $\triangle G$ ZEBOV-GP (V920) Ebola vaccine in phase I-III clinical trials across regions. Future Microbiol 2020 ; $15: 85-106$.

27. Medaglini D, Harandi AM, Ottenhoff THM, et al. Ebola vaccine R\&D: filling the knowledge gaps. Sci Transl Med $2015 ; 7: 317 p s 24$.

28. Juan-Giner A, Tchaton M, Jemmy J-P, et al. Safety of the rVSV ZEBOV vaccine against Ebola Zaire among frontline workers in Guinea. Vaccine 2019 ; 37 : 7171-7.

29. Davis C, Tipton T, Sabir S, et al. Post-exposure prophylaxis with rVSV-ZEBOV following exposure to a patient with Ebola virus disease relapse in the UK: an operational, safety and immunogenicity report. Clin Infect Dis 2019 ; nov 30 ; ciz1165. doi: 10.1093/cid/cizl165.
30. Clarke DK, Xu R, Matassov D, et al. Safety and immunogenicity of a highly attenuated rVSVN4CT1-EBOVGPI Ebola virus vaccine: a randomised, doubleblind, placebo-controlled, phase 1 clinical trial. Lancet Infect Dis 2020 ; 20 : 455-66.

31. DiNapoli JM, Yang L, Samal SK, et al. Respiratory tract immunization of nonhuman primates with a Newcastle disease virus-vectored vaccine candidate against Ebola virus elicits a neutralizing antibody response. Vaccine 2010 ; $29: 17-25$.

32. Blaney $J E$, Wirblich C, Papaneri AB, et al. Inactivated or live-attenuated bivalent vaccines that confer protection against rabies and Ebola viruses. J Virol 2011; 85 : 10605-16.

33. Bukreyev A, Marzi A, Feldmann F, et al. Chimeric human parainfluenza virus bearing the Ebola virus glycoprotein as the sole surface protein is immunogenic and highly protective against Ebola virus challenge. Virology $2009 ; 383: 348-61$.

34. Meyer M, Garron T, Lubaki NM, et al. Aerosolized Ebola vaccine protects primates and elicits lung-resident T cell responses. J Clin Invest 2015; 125 3241-55.

35. Halfmann P, Ebihara H, Marzi A, et al. Replication-deficient ebolavirus as a vaccine candidate. J Virol $2009 ; 83: 3810-5$.

36. Marzi A, Halfmann P, Hill-Batorski L, et al. Vaccines. An Ebola wholevirus vaccine is protective in nonhuman primates. Science $2015 ; 348$ : 439-42.

37. Dewitt T. Ebola vaccine inches toward human clinical trials. University of Wisconsin-Madison 2018. https://news.wisc.edu/ebola-vaccine-inchestoward-human-clinical-trials/

38. Kibuuka H, Berkowitz NM, Millard M, et al. Safety and immunogenicity of Ebola virus and Marburg virus glycoprotein DNA vaccines assessed separately and concomitantly in healthy Ugandan adults: a phase $1 b$, randomised, double-blind, placebo-controlled clinical trial. Lancet 2015; $385: 1545-54$.

39. Bengtsson KL, Song H, Stertman L, et al. Matrix-M adjuvant enhances antibody, cellular and protective immune responses of a Zaire Ebola/ Makona virus glycoprotein (GP) nanoparticle vaccine in mice. Vaccine 2016 ; $34:$ 1927-35.

40. Fries L, Cho I, Krähling V, et al. A Randomized, blinded, dose-ranging trial of an Ebola virus glycoprotein ( $E B O V$ GP) nanoparticle vaccine with matrix- $M^{T M}$ adjuvant in healthy adults. J Infect Dis $2020 ; 222: 572-82$.

41. Marzi A, Hanley PW, Haddock $\varepsilon$, et al. Efficacy of vesicular stomatitis virusEbola virus postexposure treatment in Rhesus macaques infected with Ebola virus Makona. J Infect Dis 2016 ; 214 : S360-6.

42. Falzarano D, Feldmann F, Grolla A, et al. Single immunization with a monovalent vesicular stomatitis virus-based vaccine protects nonhuman primates against heterologous challenge with Bundibugyo ebolavirus. J Infect Dis 2011 ; 204 (suppl 3) : S1082-9.

43. Natesan M, Jensen SM, Keasey SL, et al. Human survivors of disease outbreaks caused by Ebola or Marburg virus exhibit cross-reactive and longlived antibody responses. Clin Vaccine Immunol 2016; 23 : 717-24.

44. Legardy-Williams JK, Carter RJ, Goldstein ST, et al. Pregnancy outcomes among women receiving rVSVA-ZEBOV-GP Ebola vaccine during the Sierra Leone trial to introduce a vaccine against Ebola. Emerg Infect Dis $2020 ; 26$ : 541-8.

45. Kennedy SB, Bolay F, Kieh M, et al. Phase 2 placebo-controlled trial of two vaccines to prevent Ebola in Liberia. N Engl J Med 2017 ; 377 : 1438-47.

46. Mulangu S, Dodd LE, Davey RT, et al. A Randomized, controlled trial of Ebola virus disease therapeutics. N Engl J Med 2019; 381 : 2293-303.

47. Kasereka MC, Ericson AD, Conroy AL, et al. Prior vaccination with recombinant vesicular stomatitis virus-Zaire Ebolavirus vaccine is associated with improved survival among patients with Ebolavirus infection. Vaccine $2020 ; 38: 3003-7$

48. WHO prime boost ebola report https://www.who.int/immunization/research/ meetings_workshops/WHO_primeboost_Ebola_2lnovl4_meeting_report.pdf 